OPEN ACCESS

Edited by:

Ailin Barseghian,

University of California, Irvine,

United States

Reviewed by:

Teresa Padro,

Sant Pau Institute for Biomedical

Research, Spain

Jürgen Bernhagen,

Ludwig Maximilian University of

Munich, Germany

${ }^{*}$ Correspondence:

Sang-Hyun Kim

shkimmd@snu.ac.kr

Specialty section:

This article was submitted to

Cardiovascular Epidemiology and

Prevention,

a section of the journal

Frontiers in Cardiovascular Medicine

Received: 30 August 2018

Accepted: 21 March 2019

Published: 09 April 2019

Citation:

Kim H-L and Kim S-H (2019) Pulse

Wave Velocity in Atherosclerosis.

Front. Cardiovasc. Med. 6:41.

doi: 10.3389/fcrm.2019.00041

\section{Pulse Wave Velocity in Atherosclerosis}

\author{
Hack-Lyoung Kim and Sang-Hyun Kim* \\ Division of Cardiology, Department of Internal Medicine, Boramae Medical Center, Seoul National University College of \\ Medicine, Seoul, South Korea
}

Early detection of subclinical atherosclerosis is important to reduce patients' cardiovascular risk. However, current diagnostic strategy focusing on traditional risk factors or using risk scoring is not satisfactory. Non-invasive imaging tools also have limitations such as cost, time, radiation hazard, renal toxicity, and requirement for specialized techniques or instruments. There is a close interaction between arterial stiffness and atherosclerosis. Increased luminal pressure and shear stress by arterial stiffening causes endothelial dysfunction, accelerates the formation of atheroma, and stimulates excessive collagen production and deposition in the arterial wall, leading to the progression of atherosclerosis. Pulse wave velocity (PWV), the most widely used measure of arterial stiffness, has emerged as a useful tool for the diagnosis and risk stratification of cardiovascular disease (CVD). The measurement of PWV is simple, non-invasive, and reproducible. There have been many clinical studies and meta-analyses showing the association between PWV and coronary/cerebral/carotid atherosclerosis. More importantly, longitudinal studies have shown that PWV is a significant risk factor for future CVD independent of well-known cardiovascular risk factors. The measurement of PWV may be a useful tool to select subjects at high risk of developing subclinical atherosclerosis or CVD especially in mass screening.

Keywords: arterial stiffness, atherosclerosis, cardiovascular disease, pulse wave velocity, risk stratification

\section{INTRODUCTION}

Cardiovascular disease (CVD) is the leading cause of morbidity and mortality globally (1). In the majority of cases, the underlying cause of CVD is atherosclerosis (2). Atherosclerosis is a progressive disease characterized by the accumulation of lipids, inflammatory cells, and fibrous elements in the wall of large arteries causing progressive luminal narrowing of the arteries (3). Narrowed arteries limit the flow of oxygen-rich blood to vital organs such as the brain and the heart, leading to myocardial and cerebral ischemia. Sometimes, acute occlusion due to the formation of a thrombus results in serious vascular event such as acute myocardial infarction and stroke.

Arterial walls are thickened and stiffened with age $(4,5)$. This arterial remodeling process usually occurs at the level of elastic arteries, which is called "arteriosclerosis." Loss of elastic fibers and increased fibrosis of arterial walls as a consequence of repetitive cyclic stress is the main pathophysiological feature of arteriosclerosis (4). Arteriosclerosis is the stiffening or hardening of the artery walls (= arterial stiffness), and it is different from the term "atherosclerosis," which is the narrowing of the artery by the deposition of plaque (3). Atherosclerosis is a specific type of arteriosclerosis. Emerging evidence indicates that arterial stiffness is one of the earliest markers of functional and structural changes in arterial walls $(5,6)$. From clinical point of view, 
recognition, and measurement of arterial stiffness is important, because increased arterial stiffness is associated with worse cardiovascular outcomes, independent of traditional risk factors such as aging, hypertension, diabetes, dyslipidemia, obesity, and smoking (7-21). The most widely used measure of arterial stiffness is pulse wave velocity (PWV). As PWV is the measure of the speed of arterial pressure waves traveling along the aorta and large arteries, it is usually calculated by dividing distance with pressure wave transit time at the two points of recording arteries (5). The distance between the two sites along an arterial segment can be directly measured or estimated from the body height using regression model (22). The most commonly used method for estimating transit time is the foot-to-foot method: time difference between the feet of the two pulse waveforms (23). According to the two targeting arteries, various types of PWV measurements were determined such as carotid-femoral PWV (cfPWV) and brachial-ankle (baPWV). These two PWV are most widely used in clinical and research fields. In the measurement of aortic PWV, two arterial points are aortic root and descending thoracic aorta (24). Arterial pulse waveforms for PWV measurement can be obtained using applanation tonometry, echocardiography, and cardiac magnetic resonance imaging. Detailed information on specific method of each modality can be found elsewhere (5). PWV becomes faster in stiffened artery, and PWV value is elevated. The measurement of PWV is clinically valuable because it is simple, non-invasive, inexpensive, and reproducible (25).

Although there has been significant improvement in CVD prognosis by controlling risk factors such as hypertension, diabetes, and dyslipidemia, the burden of CVD is till substantial (1). It has generally been suggested that these classic risk factors cannot fully explain the increasing burden of CVD, and that more than $50 \%$ of patients with CVD do not have any of these risk factors $(26,27)$. In addition, many patients suffering from fatal CVD such as sudden cardiac death, myocardial infarction, or stroke do not have prior symptoms or warning signs $(28,29)$. Therefore, it is very important to detect subclinical atherosclerosis in early stages, and to identify individuals who are at high risk for future CVD such as angina, myocardial infarction, and stroke. Recently, special attention has been focused on PWV as a simple and reliable non-invasive tool to improve detection and risk stratification for CVD. This article will review the role of PWV in atherosclerosis and CVD.

\section{PWV IN CORONARY ARTERY ATHEROSCLEROSIS}

Recently, many studies have revealed the association between PWV and coronary atherosclerosis using cfPWV $(17,30-35)$ or baPWV (36-46). In symptomatic patients, PWV was associated with the presence and severity of coronary artery disease (CAD) assed by invasive coronary angiography (ICA) (17, 31, 32, 34, $36,37,40,45)$. It was reported that there was a strong positive correlation between CAD severity and cfPWV $(r=0.838, P$ $=0.001$ ) in 103 patients undergoing ICA (32). Hofmann et al. also used cfPWV as a measure of arterial stiffness in 155 patients undergoing ICA, and reported a positive association of elevated cfPWV with the presence and severity of CAD (34). Kim et al. investigated 501 patients with stable angina showed that baPWV is significantly associated with the presence and severity of CAD on ICA (40). In accordance with these findings, Xiong et al. measured baPWV in 321 symptomatic patients undergoing ICA, and demonstrated a significant correlation between baPWV and CAD severity assessed by SYNergy between percutaneous coronary intervention with TAXus and cardiac surgery (SYNTAX) score (45). Chung et al. reported the same finding of the positive correlation between baPWV and SYNTAX score in a study of 703 patients undergoing ICA (37). In asymptomatic diabetic population, both cfPWV and baPWV was associated with the presence and progression of coronary stenosis or plaque on computed tomography coronary angiography (CCTA) $(33,38)$. Our group investigated 470 patients with chest discomfort, and showed that baPWV has positive correlations with CAD extent and severity evaluated CCTA (39). Nam et al. evaluated 615 asymptomatic individuals, and demonstrated that elevated baPWV was an independent predictor of the presence of obstructive CAD detected by CCTA (42). Similarly, other studies enrolling healthy individuals consistently showed the positive association between PWV and coronary atherosclerosis assessed by luminal stenosis or coronary artery calcium (CAC) score on CCTA $(35,41,43,44)$. There have been a few longitudinal studies assessing the impact of baseline PWV on the development or progression of coronary atherosclerosis. Lee et al. investigated 1,124 subjects undergoing general health examination annually, and showed that baseline higher baPWV was significantly correlated with the progression of CAC during 2.7 year of follow-up (41). In a more recent study of 45 patients with type 2 diabetes, baseline cfPWV was associated with highrisk subtype of coronary plaque volume on CCTA measured after 5 -years follow-up, independently of age, sex, diabetes, and blood pressure (33).

Summary of recent studies showing the association between PWV and coronary atherosclerosis is demonstrated in Table $\mathbf{1 .}$

\section{PWV IN CEREBRAL ARTERY ATHEROSCLEROSIS}

Cerebral small vessel disease (SVD), such as cerebral microbleeds, white matter hyperintensity, or lacunar infarction, is commonly observed in older people, and it is recognized as major vascular contributor to stroke, cognitive impairment, and geriatric syndrome $(47,48)$. Previous studies have reported an association between cerebral SVD and baPWV in the general population $(49,50)$ and patients with acute ischemic stroke (51, 52), lacunar infarction (53) or CAD (54). Similar finding showing the association between increased PWV and cerebral SVD were reported in studies using cfPWV (55-57) and aortic PWV (58-60). It has also been suggested that PWV is associated with cognitive dysfunction and the longitudinal progression of cognitive decline in the elderly $(61,62)$.

PWV is also associated with large cerebral artery calcification, stenosis, or occlusion. The association between increased cfPWV and cerebral artery calcification or stenosis has been revealed in 
TABLE 1 | Summary of recent studies showing the association between pulse wave velocity and coronary atherosclerosis.

\begin{tabular}{|c|c|c|c|c|c|c|}
\hline Source & $\begin{array}{l}\text { Number of } \\
\text { patients }\end{array}$ & Population & $\begin{array}{l}\text { Mean age } \\
\text { (years) }\end{array}$ & Design & PWV & Summary of findings \\
\hline Kim et al. (38) & 83 & Type 2 diabetes & 64 & Cross-sectional & baPWV & $\begin{array}{l}\text { The AUC of baPWV for coronary artery stenosis } \\
(>20 \%) \text { on CCTA was } 0.672\end{array}$ \\
\hline Funck et al. (33) & 45 & Type 2 diabetes & 63 & Longitudinal & cfPWV & $\begin{array}{l}\text { Baseline cfPWV was associated with high-risk } \\
\text { subtype of coronary plaque volume on CCTA } \\
\text { measured after } 5 \text {-yearf follow-up, independently of } \\
\text { age, sex, diabetes, and blood pressure }\end{array}$ \\
\hline Chiha et al. (31) & 344 & $\begin{array}{l}\text { Suspected CAD } \\
\text { undergoing invasive } \\
\text { CAG }\end{array}$ & 61 & Cross-sectional & cfPWV & $\begin{array}{l}\text { cfPWV correlated with the extent of CAD, as } \\
\text { measured by the "Extent" score }(r=0.21, P= \\
0.001)\end{array}$ \\
\hline Lee et al. (41) & 1,124 & $\begin{array}{l}\text { Undergoing health } \\
\text { check-up }\end{array}$ & 44 & Longitudinal & baPWV & $\begin{array}{l}\text { Baseline higher baPWV was significantly correlated } \\
\text { with the progression of CAC during } 2.7 \text { year of } \\
\text { follow-up }\end{array}$ \\
\hline Vishnu et al. (44) & 1,131 & $\begin{array}{l}\text { Community } \\
\text { population (men) }\end{array}$ & 45 & Cross-sectional & baPWV & baPWV was associated with the presence of CAC \\
\hline Torii et al. (43) & 986 & $\begin{array}{l}\text { Community } \\
\text { population }\end{array}$ & 986 & Cross-sectional & baPWV & $\begin{array}{l}\text { Prevalence of CAC progressively increased with } \\
\text { rising levels of baPWV. }\end{array}$ \\
\hline Cainzos-Achirica et al. (46) & 15,185 & $\begin{array}{l}\text { Undergoing health } \\
\text { check-up }\end{array}$ & 42 & Cross-sectional & baPWV & $\begin{array}{l}\text { The multivariable-adjusted odds ratios for } \mathrm{CAC}>0 \\
\text { comparing baPWV quintiles } 2-5 \text { vs. quintile } 1 \text { were } \\
1.06,1.24,1.39 \text {, and } 1.60 \text {, respectively }(P \\
\text { trend }<0.001)\end{array}$ \\
\hline Duman et al. (32) & 103 & $\begin{array}{l}\text { Suspected CAD } \\
\text { undergoing invasive } \\
\text { CAG }\end{array}$ & 55 & Cross-sectional & cfPWV & $\begin{array}{l}\text { A highly positive correlation was observed between } \\
\text { CAD severity and PWV }(r=0.838, P=0.001)\end{array}$ \\
\hline Braber et al. (35) & 193 & Sportsmen & 55 & Cross-sectional & cfPWV & $\begin{array}{l}\text { Adding cfPWV to traditional risk factor models did } \\
\text { not change the AUC from } 0.78 \text { to AUC } 0.78(P= \\
0.99) \text { for prediction of CAD on CCTA }\end{array}$ \\
\hline Kim et al. (39) & 470 & $\begin{array}{l}\text { Suspected CAD } \\
\text { undergoing CCTA }\end{array}$ & 470 & Cross-sectional & baPWV & $\begin{array}{l}\text { baPWV showed significant correlation with segment } \\
\text { stenosis score, segment involvement score, CAC, } \\
\text { and the number of segment with non-calcified } \\
\text { plaque, mixed plaque, and calcified plaque on } \\
\text { CCTA, respectively }\end{array}$ \\
\hline Hofmann et al. (34) & 155 & $\begin{array}{l}\text { Undergoing coronary } \\
\text { bypass surgery }\end{array}$ & 67 & Cross-sectional & cfPWV & $\begin{array}{l}\text { cfPWV was strongly associated with the severity of } \\
\text { the patients' CAD }(P<0.001)\end{array}$ \\
\hline Chung et al. (37) & 703 & $\begin{array}{l}\text { Suspected CAD } \\
\text { undergoing invasive } \\
\text { CAG }\end{array}$ & 73 & Cross-sectional & baPWV & $\begin{array}{l}\text { baPWV was significantly associated with the } \\
\text { SYNTAX score }\left(R^{2}=0.525, P<0.001\right)\end{array}$ \\
\hline Kim et al. (40) & 501 & $\begin{array}{l}\text { Suspected CAD } \\
\text { undergoing invasive } \\
\text { CAG }\end{array}$ & 59 & Cross-sectional & baPWV & $\begin{array}{l}\text { baPWV was significantly associated with modified } \\
\text { Gensini stenosis score }(P=0.033) \text { and vessel } \\
\text { disease score }(P<0.001) \text { even after controlling for } \\
\text { potential confounders }\end{array}$ \\
\hline Chae et al. (36) & 651 & $\begin{array}{l}\text { Suspected CAD } \\
\text { undergoing invasive } \\
\text { CAG }\end{array}$ & 58 & Cross-sectional & baPWV & $\begin{array}{l}\text { baPWV was associated with the presence of } \\
\text { obstructive CAD but not with CAD extent }\end{array}$ \\
\hline Bechlioulis et al. (30) & 393 & $\begin{array}{l}\text { Suspected CAD } \\
\text { undergoing invasive } \\
\text { CAG }\end{array}$ & 61 & Cross-sectional & cfPWV & $\begin{array}{l}\text { Increased cfPWV was associated with CAD in } \\
\text { overweight and obese patients (body mass } \\
\text { index } \geq 25 \mathrm{~kg} / \mathrm{m}^{2} \text {; waist circumference } \geq 94 \mathrm{~cm} \text { in } \\
\text { men and } \geq 80 \mathrm{~cm} \text { in women; } P<0.05 \text { ) }\end{array}$ \\
\hline Xiong et al. (45) & 321 & $\begin{array}{l}\text { Suspected CAD } \\
\text { undergoing invasive } \\
\text { CAG }\end{array}$ & 65 & Cross-sectional & baPWV & $\begin{array}{l}\text { Multivariable analysis showed that baPWV was } \\
\text { independently associated with the SYNTAX score } \\
(P<0.001)\end{array}$ \\
\hline Nam et al. (42) & 615 & $\begin{array}{l}\text { Undergoing health } \\
\text { check-up }\end{array}$ & 53 & Cross-sectional & baPWV & $\begin{array}{l}\text { baPWV was associated with obstructive CAD on } \\
\text { CCTA. The optimal cut-off value for the detection of } \\
\text { obstructive CAD was } 1,426 \mathrm{~cm} / \mathrm{s}\end{array}$ \\
\hline
\end{tabular}

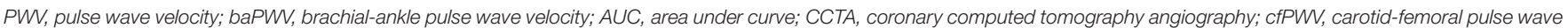

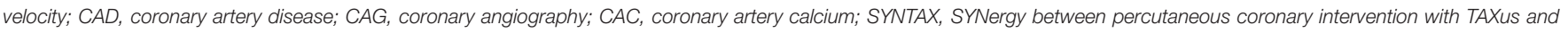
cardiac surgery. 
hypertensive subjects (63) and in patients with acute ischemic stroke (64). A case-control study performed in Japan has indicated that a higher baPWV, in addition to traditional risk factors, is associated with a higher risk of cerebral infarction (65). In that study, baPWV $\geq 16 \mathrm{~m} / \mathrm{s}$ had about three times higher risk of cerebral infarction compared to those with baPWV $<16$ $\mathrm{m} / \mathrm{s}$. baPWV was significantly correlated with cerebral artery calcification or stenosis in patient with acute ischemic stroke $(51,66)$. However, there was also a negative report showing that a significant association between baPWV and ischemic stroke was abolished after controlling for potential confounders such as high blood pressure (BP) (67). The authors also showed that baPWV was not independently associated with the severity of white matter hyperintensity lesion or cerebral microbleeds (67).

Summary of recent studies showing the association between PWV and crebral atherosclerosis is demonstrated in Table 2.

\section{PWV IN CAROTID ARTERY ATHEROSCLEROSIS}

Carotid intima-media thickness (IMT) is a marker of atherosclerosis, and is associated with CAD and stroke $(68,69)$. There was a positive linear correlation between carotid IMT and cfPWV in general population (70-73), hypertensive (74), and diabetic patients (72). Kubozono et al. first reported that high baPWV was a strong predictor of increased carotid IMT $(\geq 1.0 \mathrm{~mm})$ in 1,583 Japanese male subjects undergoing routine health check-up (75). Following cross-sectional studies have also showed the association between baPWV and increased carotid IMT or carotid plaque formation in general population (76), and patients with type 2 diabetes (77), end-stage renal disease (78), and cerebral artery thrombosis (79). Other PWV of other arterial tree segments including carotid-cerebral PWV (80), aorto-popliteal PWV (81), and heart-carotid PWV (82) also showed significant association with carotid atherosclerosis. A recently published longitudinal study showed that baPWV was independently associated with the risk of carotid plaque formation (83). As similar findings, baseline cfPWV was independently associated with an increase in carotid IMT during the 4-year follow-up (84). However, another study involving patients with acute ischemic stroke, revealed that baPWV was associated with the burden of intracranial atherosclerosis but not with extracranial carotid atherosclerosis (51). Lu et al. demonstrated that, only cfPWV, but not baPWV showed significant association with carotid IMT in general population (71).

Summary of recent studies showing the association between PWV and carotid atherosclerosis is demonstrated in Table 3.

\section{PREDICTIVE VALUE OF PWV}

The predictive value of PWV for the occurrence of CVD has been reported in the general population and patients with various clinical conditions. Mattace-Raso et al. investigated 2,835 community healthy subjects and showed that cfPWV is an independent predictor of coronary heart disease and stroke during 4 years of clinical follow-up (7). Another population study involving 1,678 community subjects over a median followup of 9.4 years, showed a similar finding that aortic PWV predicted composite cardiovascular outcomes beyond traditional risk factors (8). PWV also play a role as an independent predictor of future CVD in patients with hypertension $(13,16)$, diabetes (15), end-stage renal disease (17), stroke $(14,18)$, and CAD $(19,20)$.

There are several meta-analyses showing the prognostic value of PWV for the future cardiovascular events. A meta-analysis of 10 studies showed that increased cfPWV is a significant predictor of future CVD independent of Framingham risk factors (21). More recent meta-analysis of 19 studies have reported similar finding showing the association between cfPWV and CVD: $1 \mathrm{~m} / \mathrm{s}$ increase of cfPWV was associated with 1.12-fold increase future CVD events (85). Findings based on individual participant metaanalysis of 17,636 subjects from 16 studies demonstrated that per 1-SD change in $\log _{e} \mathrm{cfPWV}$ was an independent predictor for future CVD events by 1.45 -fold (86). In regard to baPWV, a metaanalysis of 12 cohort studies indicated that an increase of $1 \mathrm{~m} / \mathrm{s}$ of baPWV was associated with a $12 \%$ increase in the risk of CVD (9). More recently, meta-analysis of 14,673 Japanese participants without preexisting CVD showed that every 1 -standard deviation (SD) increase of the baPWV was associated with a 1.19-fold increase in the risk of CVD during 6.4-year follow-up period (87).

\section{MEAN AND CUTOFF VALUE OF PWV}

As PWV value can be affected by many clinical factors such as age and blood pressure, mean, or cutoff values of PWV are various among study population. However, PWV value are usually higher in patients with CVD than those without. cfPWV is higher in subjects with CVD (ranged $6 \sim 9 \mathrm{~m} / \mathrm{s})(34,35,88)$ than those without (ranged $8 \sim 13 \mathrm{~m} / \mathrm{s})(31,34,64,88)$. In middle aged and elderly subjects, mean baPWV value has been reported ranged $15 \sim 18 \mathrm{~m} / \mathrm{s}(42,46,75,83)$, and $13 \sim 15 \mathrm{~m} / \mathrm{s}(38,40,89)$ in with and without CVD or its risk factors, respectively. Several studies have indicated cutoff value of PWV in the prediction of atherosclerosis or cardiovascular events, which is summarized in Table 4. Current guidelines suggested that cfPWV $>10 \mathrm{~m} / \mathrm{s}$ and baPWV $>18 \mathrm{~m} / \mathrm{s}$ are indicative of individual's high risk in current guidelines in Europe (90) and Japan (25), respectively.

\section{MECHANISMS LINKING PWV AND ATHEROSCLEROSIS}

Mechanisms linking arterial stiffness and atherosclerosis have not been well-elucidated. However, several hypotheses could be suggested. Increased arterial stiffness leads to increased BP, and promote vascular remodeling (91). Also, increased luminal pressure and shear stress accelerates the formation of atheroma, and stimulates excessive collagen production and deposition in the arterial wall, leading to the progression of atherosclerosis (92). In addition, increased pulse pressure may be associated with the development of plaque and later its rupture (26). Indeed, both arterial stiffening and plaque formation depend 
TABLE 2 | Summary of recent studies showing the association between pulse wave velocity and cerebral artery atherosclerosis.

\begin{tabular}{|c|c|c|c|c|c|c|}
\hline Source & $\begin{array}{l}\text { Number of } \\
\text { patients }\end{array}$ & Population & $\begin{array}{l}\text { Mean age } \\
\text { (years) }\end{array}$ & Design & PWV & Summary of findings \\
\hline Zhai et al. (50) & 953 & Community population & 56 & Cross-sectional & baPWV & $\begin{array}{l}\text { Increased baPWV was associated with most of } \\
\text { imaging markers of SVD, including dilated PVS in } \\
\text { white matter, larger WMH volume, and marginally } \\
\text { associated with strictly lobar CMB }\end{array}$ \\
\hline Tabata et al. (54) & 149 & Coronary artery disease & 71 & Cross-sectional & baPWV & $\begin{array}{l}\text { A multivariate analysis showed that baPWV were } \\
\text { predictors of lacunar infarcts and CBM }\end{array}$ \\
\hline Kim et al. (52) & 1,282 & $\begin{array}{l}\text { Acute ischemic stroke } \\
\text { or TIA }\end{array}$ & 68 & Cross-sectional & baPWV & $\begin{array}{l}\text { On multivariate analysis, an increase in baPWV was } \\
\text { associated with chronic lacunes, WMH, deep CMB, } \\
\text { acute SVD, combined SVD score }>1 \text {, and } \\
\text { combined SVD score }>2\end{array}$ \\
\hline Rosano et al. (57) & 273 & Community population & 83 & Longitudinal & cfPWV & $\begin{array}{l}\text { Higher cfPWV in 1997-1998 was associated with } \\
\text { greater WMH volume in } 2006-2008 \text { within the left } \\
\text { superior longitudinal fasciculus }\end{array}$ \\
\hline King et al. (59) & 1,270 & Community population & 51 & Cross-sectional & aPWV & $\begin{array}{l}\text { An increase in aortic PWV was related to an } \\
\text { increase in subsequent WMH volume }\end{array}$ \\
\hline Poels et al. (56) & 1,460 & Community population & 58 & Cross-sectional & cfPWV & $\begin{array}{l}\text { Higher cfPWV was associated with larger white } \\
\text { matter lesion volume but not with lacunar infarcts or } \\
\text { microbleeds }\end{array}$ \\
\hline Kim et al. (51) & 801 & Acute ischemic stroke & 64 & Cross-sectional & baPWV & $\begin{array}{l}\text { Increased baPWV was associated with the } \\
\text { presence of atherosclerosis ( } \geq 50 \% \text { stenosis) in the } \\
\text { intracranial cerebral artery, but not with } \\
\text { atherosclerosis in the extracranial cerebral artery }\end{array}$ \\
\hline Zhang et al. (63) & 270 & Hypertensive & 61 & Cross-sectional & cfPWV & $\begin{array}{l}\text { cfPWV was independently associated with stenosis } \\
\text { or calcification of intracranial artery }\end{array}$ \\
\hline Kim et al. (53) & 120 & Lacunar infarction & 64 & Cross-sectional & baPWV & $\begin{array}{l}\text { Patients with higher baPWV were more likely to } \\
\text { have multiple lacunar infarcts and more severe white } \\
\text { matter lesions }\end{array}$ \\
\hline van Elderen et al. (60) & 86 & Type 1 diabetes & 47 & Cross-sectional & aPWV & $\begin{array}{l}\text { Aortic PWV was independently associated with } \\
\text { cerebral WMHs but not with cerebral microbleeds or } \\
\text { lacunar infarcts }\end{array}$ \\
\hline Ochi et al. (49) & 443 & $\begin{array}{l}\text { Apparently healthy } \\
\text { population }\end{array}$ & 67 & Cross-sectional & baPWV & $\begin{array}{l}\text { OR of a high baPWV, defined as } \geq 1,500 \mathrm{~cm} / \mathrm{s} \text {, for } \\
\text { the presence of CBM was } 6.05 \text { even after } \\
\text { correction for confounding parameters, including } \\
\text { age and hypertension }\end{array}$ \\
\hline Brandts et al. (58) & 50 & Hypertensive & 49 & Cross-sectional & aPWV & $\begin{array}{l}\text { Aortic PWV was statistically significantly associated } \\
\text { with lacunar brain infarcts }(\mathrm{OR}=1.8, P=0.04) \text {, } \\
\text { independent of age, sex, and hypertension duration, } \\
\text { but not with WMH }\end{array}$ \\
\hline Park et al. (66) & 67 & Acute ischemic stroke & 65 & Cross-sectional & baPWV & $\begin{array}{l}\text { baPWV was significantly correlated with cerebral } \\
\text { arterial calcification }(r=0.524, P<0.001)\end{array}$ \\
\hline De Silva et al. (64) & 268 & Acute ischemic stroke & 62 & Cross-sectional & cfPWV & $\begin{array}{l}\text { cfPWV was significantly higher in patients with } \\
\text { significant stenosis of intracranial artery than those } \\
\text { without }\end{array}$ \\
\hline Choi et al. (67) & 223 & Stroke & 66 & Cross-sectional & baPWV & $\begin{array}{l}\text { Multiple regression analysis revealed that the } \\
\text { baPWV was not independently associated with } \\
\text { increased risk of stroke, or the severity of } \mathrm{WMH} \text { or } \\
\mathrm{CMB}\end{array}$ \\
\hline Henskens et al. (55) & 167 & General population & 52 & Cross-sectional & cfPWV & $\begin{array}{l}\text { A higher cfPWV was significantly associated with a } \\
\text { greater volume of WMH and the presence of } \\
\text { lacunar infarcts but not with CBM }\end{array}$ \\
\hline
\end{tabular}

PWW, pulse wave velocity; baPWV, brachial-ankle pulse wave velocity; SVD, small vessel disease; PVS, perivascular space, WMH, white matter hyperintensity; CBMs, cerebral microbleed; TIA, transient ischemic attack; cfPWV: carotid-femoral pulse wave velocity; aPWV, aortic pulse wave velocity; OR, odds ratio.

partly on the same systemic pathophysiological process causing the accumulation of extracellular matrix in the arterial walls $(3,4,93)$. Shared common risk factors such as hypertension, diabetes mellitus, and dyslipidemia may be another important mechanism linking PWV and atherosclerosis $(5,94)$. Mechanical aspect should be also considered in coronary atherosclerosis. Systolic BP increases and diastolic BP decreases in the stiffened artery $(5,95)$. Increased systolic $B P$ and pulse pressure 
TABLE 3 | Summary of recent studies showing the association between pulse wave velocity and carotid artery atherosclerosis.

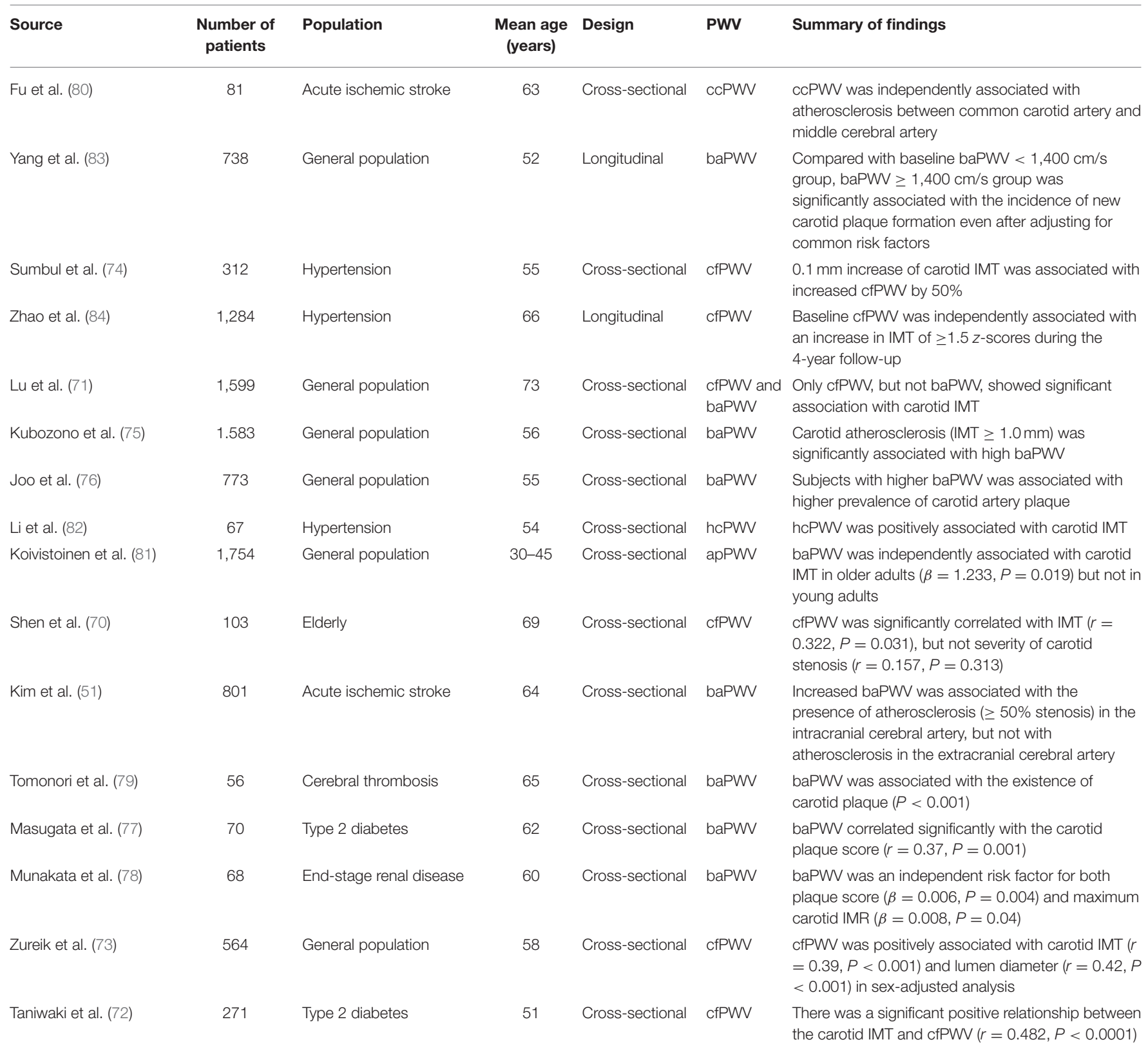

PWW, pulse wave velocity; ccPWV, carotid-cerebral pulse wave velocity; baPW, brachial-ankle pulse wave velocity; IMT, intima-media thickness; hcPWV, heart-carotid pulse wave velocity; apPW, aorto-popliteal pulse wave velocity.

are hemodynamic burdens to the left ventricle leading to ventricular hypertrophy, and decreased diastolic BP is associated with reduced coronary perfusion $(95,96)$. Two well-known major risk factors for cerebral SVD are age and high BP (97), which are also major determinants of PWV. Increased pulse pressure by arterial stiffening may lead to endothelial dysfunction, and damages the microcirculation and bloodbrain barrier, finally leading to both cerebral large artery atherosclerosis and SVD (95, 98, 99). Possible mechanisms linking arterial stiffness and atherosclerosis are demonstrated in Figure 1.

\section{CLINICAL IMPLICATIONS}

Recognition of subclinical atherosclerotic vascular changes before clinical manifestation in an asymptomatic population is important for risk stratification and optimal management, which finally leads to the prevention of $\operatorname{CVD}(98,100)$. Intensive modification of traditional risk factors has significantly reduced the development of CVD; however, the high residual prevalence of CVD requires further improvements in identification and risk stratification strategies. It has been suggested that the value of traditional risk factors such as hypertension, 
TABLE 4 | Summary of recent studies showing cut-off value of PWV in the prediction of atherosclerosis or future cardiovascular events.

\begin{tabular}{|c|c|c|c|c|c|}
\hline Source & $\begin{array}{c}\text { Number of } \\
\text { patients }\end{array}$ & Population & $\begin{array}{l}\text { Mean age Design } \\
\text { (years) }\end{array}$ & PWV & Summary of findings \\
\hline
\end{tabular}

Kim et al. (38)

83

Type 2 diabetes

64

Yang et al. (83)

738

General population

Kubozono et al. (75)

1.583

General population

56

Cross-sectional baPWV
Chiha et al. (31)

Cainzos-Achirica et al. (46)

15,185
Suspected CAD undergoing invasive CAG

Undergoing health check-up
Lee et al. (89)

Braber et al. (35)

Chung et al. (37)

Kim et al. (40)

Gasecki et al. (14)
Nam et al. (42)
Suspected CAD undergoing CCTA

193

703

Suspected CAD undergoing invasive $\mathrm{CAG}$

Suspected CAD undergoing invasive CAG

134

Acute ischemic stroke

615
Suspected CAD undergoing myocardial SPECT

Sportsmen
Undergoing health check-up
Cross-sectional baPWV

61

Cross-sectional cfPWV

Cross-sectional baPWV

Longitudinal baPWV

Cross-sectional cfPWV
Cross-sectional baPWV

Cross-sectional baPWV

Longitudinal

cfPWV
53
Mean baPWV value of study population was 17.9 $\mathrm{m} / \mathrm{s}$. The optimal cutoff value of baPWV for the detection of coronary artery stenosis ( $\geq 20 \%$ ) was $16.5 \mathrm{~m} / \mathrm{s}$ with a sensitivity $68.9 \%$ and a specificity $63.2 \%$

Mean baPWV value of study population was 15.1 $\mathrm{m} / \mathrm{s}$. Compared with baseline baPWV $<14 \mathrm{~m} / \mathrm{s}$ group, baPWV $\geq 14 \mathrm{~m} / \mathrm{s}$ group was significantly associated with the incidence of new carotid plaque formation even after adjusting for common risk factors

Mean baPWV value of study population was 15.3 $\mathrm{m} / \mathrm{s}$. baPWV > $16.2 \mathrm{~m} / \mathrm{s}$ was optimal cutoff value for detection of the presence of carotid atherosclerosis (carotid IMT $\geq 1 \mathrm{~mm}$ ) (sensitivity $64 \%$ and specificity $71 \%$

Mean cfPWV value of study population was 12.4 $\mathrm{m} / \mathrm{s}$. Patients with cfPWV $\geq 10 \mathrm{~m} / \mathrm{s}$ was associated with higher coronary extent score than those with cfPWV $<10 \mathrm{~m} / \mathrm{s}$

Mean baPWV value of study population was 13.3 $\mathrm{m} / \mathrm{s}$. baPWV > $13.5 \mathrm{~m} / \mathrm{s}$ had a sensitivity for CAC > 100 of $70 \%$ and a specificity of $59 \%$. baPWV > $14.3 \mathrm{~m} / \mathrm{s}$ had a sensitivity for CAC > 100 of $78 \%$ and a specificity of $51 \%$

Mean baPWV value of study population was 14.8 $\mathrm{m} / \mathrm{s}$. baPWV > $15.5 \mathrm{~m} / \mathrm{s}$ was optimal cutoff value for detection of the presence and severity of obstructive CAD ( $\geq 50 \%$ ) (sensitivity $56.6 \%$ and specificity $79.7 \%)$

baPWV $\geq 17.9 \mathrm{~m} / \mathrm{s}$ was independently associated with worse cardiovascular outcome

Mean baPWV value of study population was 8.3 $\mathrm{m} / \mathrm{s}$. For the cfPWV $>8.3 \mathrm{~m} / \mathrm{s}$, the sensitivity to detect CAD was $43 \%$, specificity $69 \%$, positive predictive value $31 \%$ and negative predictive value was $79 \%$

Mean baPWV value of patients with CAD was 18.4 $\mathrm{m} / \mathrm{s}$. baPWV $>17.3 \mathrm{~m} / \mathrm{s}$ had a sensitivity of $55.6 \%$ and specificity of $62.4 \%$ in predicting coronary stenosis

Mean baPWV value of study population was 15.9 $\mathrm{m} / \mathrm{s}$. baPWV $>17 \mathrm{~m} / \mathrm{s}$ was significantly associated with the presence and severity of obstructive CAD ( $\geq 50 \%$ )

Mean cfPWV value of study population was 8.3 $\mathrm{m} / \mathrm{s}$. cfPWV $\geq 9 \mathrm{~m} / \mathrm{s}$ was associated with worse clinical outcome at hospital discharge with a specificity $61.5 \%$ and sensitivity $77.3 \%$

Mean baPWV value of patients with CAD was 14.3 $\mathrm{m} / \mathrm{s}$. The optimal cut-off value for the detection of obstructive CAD was $14.3 \mathrm{~m} / \mathrm{s}$, which had a sensitivity of $77 \%$ and a specificity of $63 \%$

PWV, pulse wave velocity; baPWV, brachial-ankle pulse wave velocity; CAD, coronary artery disease; CAG, coronary angiography; cfPWV, carotid-femoral pulse wave velocity; CAC, coronary artery calcium; SPECT, single-photon emission computed tomography. 


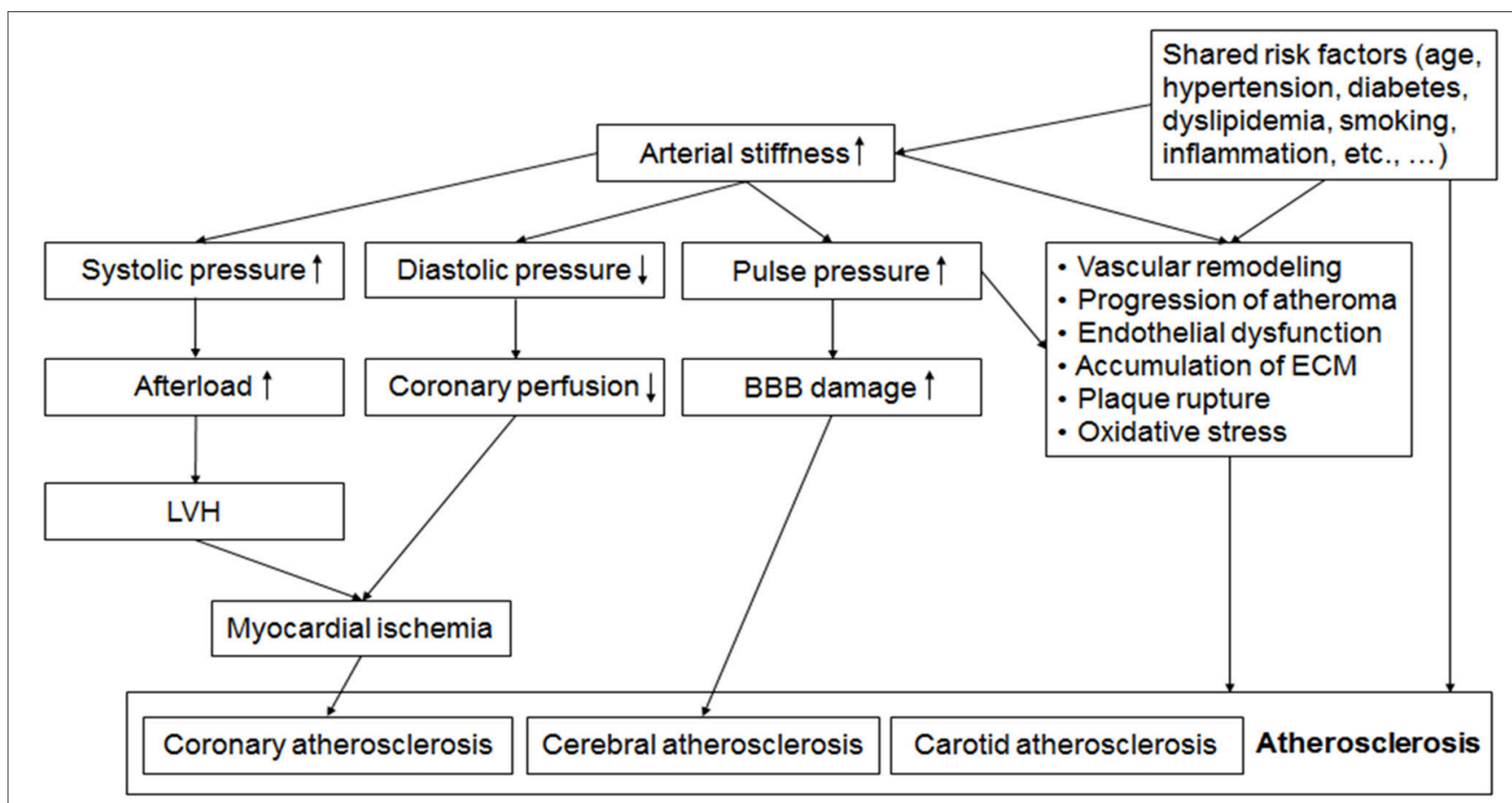

FIGURE 1 | Possible mechanisms linking arterial stiffness and atherosclerosis. Alteration of pulsatile hemodynamics by increased arterial stiffness is associated with left ventricular hypertrophy (LVH), reduced coronary perfusion and the damage of blood brain barrier (BBB), which leads to coronary and cerebral atherosclerosis. Endothelial dysfunction, oxidative stress, vascular remodeling, accumulation of extracellular matrix (ECM), and shared common risk factors such as aging, hypertension, diabetes, and dyslipidemia are also factors linking increased arterial stiffness and the development and progression of atherosclerosis. BBB, blood brain barrier; ECM, extracellular matrix; LVH, left ventricular hypertrophy.

diabetes, dyslipidemia, and smoking for the identification of atherosclerotic burden in an asymptomatic population are limited (101). Also, several scoring strategies for CVD estimation are not sufficient to identify high risk subjects (102). In this purpose, several non-invasive tests such as carotid ultrasound, coronary computed tomography, and magnetic resonance imaging have been developed, and these tests are recommended for the evaluation of subclinical atherosclerosis especially in subjects with intermediate or uncertain risk (103). However, these imaging modalities are expensive, nephrotoxic, and hazardous in terms of radiation exposure and require specialized techniques or instruments. Arterial stiffening is one of the earliest manifestations of vascular damage, arteriosclerosis, and atherosclerosis. This functional and structural changes in arterial wall can be detected using PWV which a simple, noninvasive, simple and reliable measurement. As mentioned above, many cross-sectional and longitudinal studies have indicated that PWV can detect subclinical atherosclerosis and predict future CVD. PWV allows a greater convenience of screening subclinical atherosclerosis in the general population. Improved ability to identify high risk patients would lead to better risk stratification and more effective preventive therapy. Recent studies have also shown an additional role of PWV for the diagnosis and prediction of future cardiovascular events when combined with other tests $(89,104,105)$. Additionally, PWV can be a target or monitoring tool for CVD risk-lowing therapeutic intervention $(5,95)$. Various pharmacological and non-pharmacological approaches able to reduce PWV (5) may offer potential advantages in the management of patients at high risk of CVD. However, further studies are required to confirm whether PWV reduction by this approach can directly prevent CVD.

\section{COMPARISONS BETWEEN CfPWV AND baPWV}

cfPWV measurement started in the 1960s (106), and thus, it has been most validated, and has a large amount of clinical data. cfPWV is a direct measurement, and it corresponds to the widely accepted propagative model of arterial system (107). Since aorta and its first branches are responsible for the most of the pathophysiological effects of arterial stiffness (107), cfPWV has been considered as the gold standard measurement of large artery stiffness (108). However, cfPWV measurement requires some skills, and carotid and femoral pulse acquisition are difficult especially in obese patients (107). In addition, palpation of carotid and femoral arteries causes patients' discomfort. By these reasons, the primary use of cfPWV remains in research settings, and it has not yet been implemented in clinical practice. In 2000, a more simplified method for the evaluation of arterial stiffness has been developed in Japan (109). Compared to cfPWV, 
TABLE 5 | Comparisons between cfPWV and baPWV (25, 110-112).

\begin{tabular}{|c|c|c|}
\hline & cfPWV & baPWV \\
\hline \multirow[t]{4}{*}{ Strength } & - Includes only elastic arteries & - Simple to measure \\
\hline & $\begin{array}{l}\text { - More abundant clinical data, } \\
\text { and most validated }\end{array}$ & - Convenient to patients \\
\hline & $\begin{array}{l}\text { - Considered as gold standard } \\
\text { a measure of arterial stiffness }\end{array}$ & - Useful in mass screening \\
\hline & - Widely used worldwide & \\
\hline \multirow[t]{4}{*}{ Limitation } & $\begin{array}{l}\text { - The measurement needs } \\
\text { technical skill }\end{array}$ & $\begin{array}{l}\text { - Includes both elastic and } \\
\text { muscular arteries }\end{array}$ \\
\hline & $\begin{array}{l}\text { - The measurement causes } \\
\text { discomfort }\end{array}$ & $\begin{array}{l}\text { - Invalid height-based formula } \\
\text { to estimate arterial path } \\
\text { length }\end{array}$ \\
\hline & $\begin{array}{l}\text { - Less useful in mass } \\
\text { screening }\end{array}$ & $\begin{array}{l}\text { - Inaccurate in patients with } \\
\text { peripheral arterial stenosis or } \\
\text { aortic disease }\end{array}$ \\
\hline & & $\begin{array}{l}\text { - Mainly used in Asian } \\
\text { countries }\end{array}$ \\
\hline
\end{tabular}

baPWV is easier, less time-consuming, and less stressful for the patients, because baPWV value can be obtained by just wrapping pressure cuffs of upper arms and ankles. There have been many clinical data showing the usefulness of baPWV in the prediction of organ damage and cardiovascular outcomes in general population and patients with various medical conditions. However, there are several criticism on baPWV measurement (110): (1) baPWV includes large portion of peripheral muscular artery although muscular arteries may not be relevant for the CV risk assessment, (2) the height-based formula to estimate pulse transit distance for the calculation of baPWV is not validated, (3) the value of baPWV is usually higher than other PWV, because it overestimates arterial path lengths, and includes fast pulse wave traveling toward legs $(22,110)$, and (4) baPWV is underestimated in subjects with arterial stenosis of extremities, aortic aneurysm, or aortic stenosis, otherwise, it is overestimated in subjects with aortic regurgitation (111). Therefore, application of a more specific exclusion criteria is important in baPWV researches of cohorts with severe disease. It has been generally suggested that patients with ankle-brachial index $<0.9$ should be excluded when using baPWV for any purpose $(25,111)$. Comparisons of strengths and limitations between cfPWV and baPWV are summarized in Table 5.

\section{REFERENCES}

1. Benjamin EJ, Virani SS, Callaway CW, Chamberlain AM, Chang AR, Cheng S, et al. Heart disease and stroke statistics2018 update: a report from the american heart association. Circulation. (2018) 137:e67-492. doi: 10.1161/CIR.00000000000 00558

2. Nabel EG, Braunwald E. A tale oref coronary artery disease and myocardial infarction. N Engl J Med. (2012) 366:54-63. doi: 10.1056/NEJMra11 12570

3. Lusis AJ. Atherosclerosis. Nature. (2000) 407:233-41. doi: 10.1038/35025203

4. Lee HY, Oh BH. Aging and arterial stiffness. Circ J. (2010) 74:2257-62. doi: 10.1253/circj.CJ-10-0910

\section{LIMITATIONS OF PWV}

Although information of PWV is useful in the early detection and risk prediction of cardiovascular disease, incorporation of PWV measurement in routine clinical practice has been barely performed, mainly due to several limitations of PWV. During the PWV measurement, distance between target points of arteries should be measured precisely because small inaccuracies may cause a greater error in the absolute value of PWV. Therefore, it is very important to recognize the differences in the methods used to assess path length, especially when comparing results between patient group and among different studies (107). In addition, the interpretation of PWV value should be cautious because many clinical factors affect the PWV value such as age, BP, and other cardiovascular risk factors (23). In particular, the most powerful confounders of $\mathrm{PWV}$ interpretation is BP. Increased BP augments the arterial wall tension and adds functional arterial stiffness. Therefore, BP effect should be controlled during the analysis using PWV. Although there have been few studies showing that several methods such as anti-hypertensive medications, exercise, statin, and smoking cessation improves arterial stiffness and decreases PWV value $(5,25)$, these results are from small-sized and non-randomized studies. Randomized control studies with large sample size on whether PWV-based management improves patients' outcome and the quality of daily clinical practice are required.

\section{CONCLUSIONS}

PWV is well-correlated with the presence and extent of coronary, cerebral, and carotid atherosclerosis. More importantly, PWV had a predictive value in CVD beyond traditional risk factors in the general population and patients with various diseases. Considering its non-invasiveness, simplicity and abundant clinical data, measurement of PWV may be a useful tool to select subjects at a high risk of developing atherosclerosis especially in mass screening.

\section{AUTHOR CONTRIBUTIONS}

H-LK participate in drafting the manuscript, and S-HK participate in revising the manuscript.

5. Cavalcante JL, Lima JA, Redheuil A, Al-Mallah MH. Aortic stiffness: current understanding and future directions. J Am Coll Cardiol. (2011) 57:1511-22. doi: 10.1016/j.jacc.2010.12.017

6. Cohn JN, Quyyumi AA, Hollenberg NK, Jamerson KA. Surrogate markers for cardiovascular disease: functional markers. Circulation. (2004) 109(25 Suppl. 1):Iv31-46. doi: 10.1161/01.CIR.0000133442.99 186.39

7. Mattace-Raso FU, van der Cammen TJ, Hofman A, van Popele NM, Bos ML, Schalekamp MA, et al. Arterial stiffness and risk of coronary heart disease and stroke: the Rotterdam Study. Circulation. (2006) 113:657-63. doi: 10.1161/CIRCULATIONAHA.105.555235

8. Willum-Hansen T, Staessen JA, Torp-Pedersen C, Rasmussen S, Thijs L, Ibsen $\mathrm{H}$, et al. Prognostic value of aortic pulse wave velocity as index of 
arterial stiffness in the general population. Circulation. (2006) 113:664-70. doi: 10.1161/CIRCULATIONAHA.105.579342

9. Vlachopoulos C, Aznaouridis K, Stefanadis C. Prediction of cardiovascular events and all-cause mortality with arterial stiffness: a systematic review and meta-analysis. J Am Coll Cardiol. (2010) 55:1318-27. doi: 10.1016/j.jacc.2009.10.061

10. Hansen TW, Staessen JA, Torp-Pedersen C, Rasmussen S, Li Y, Dolan E, et al. Ambulatory arterial stiffness index predicts stroke in a general population. $J$ Hypertens. (2006) 24:2247-53. doi: 10.1097/01.hjh.0000249703.57 478.78

11. Sutton-Tyrrell K, Najjar SS, Boudreau RM, Venkitachalam L, Kupelian V, Simonsick EM, et al. Elevated aortic pulse wave velocity, a marker of arterial stiffness, predicts cardiovascular events in well-functioning older adults. Circulation. (2005) 111:3384-90. doi: 10.1161/CIRCULATIONAHA.104.483628

12. Najjar SS, Scuteri A, Shetty V, Wright JG, Muller DC, Fleg JL, et al. Pulse wave velocity is an independent predictor of the longitudinal increase in systolic blood pressure and of incident hypertension in the Baltimore Longitudinal Study of Aging. J Am Coll Cardiol. (2008) 51:1377-83. doi: 10.1016/j.jacc.2007.10.065

13. Laurent S, Katsahian S, Fassot C, Tropeano AI, Gautier I, Laloux B, et al. Aortic stiffness is an independent predictor of fatal stroke in essential hypertension. Stroke. (2003) 34:1203-6. doi: 10.1161/01.STR.0000065428.03209.64

14. Gasecki D, Rojek A, Kwarciany M, Kowalczyk K, Boutouyrie P, Nyka W, et al. Pulse wave velocity is associated with early clinical outcome after ischemic stroke. Atherosclerosis. (2012) 225:348-52. doi: 10.1016/j.atherosclerosis.2012.09.024

15. Cruickshank K, Riste L, Anderson SG, Wright JS, Dunn G, Gosling RG. Aortic pulse-wave velocity and its relationship to mortality in diabetes and glucose intolerance: an integrated index of vascular function? Circulation. (2002) 106:2085-90. doi: 10.1161/01.CIR.0000033824.02 722.F7

16. Boutouyrie P, Tropeano AI, Asmar R, Gautier I, Benetos A, Lacolley P, et al. Aortic stiffness is an independent predictor of primary coronary events in hypertensive patients: a longitudinal study. Hypertension. (2002) 39:10-5. doi: 10.1161/hy0102.099031

17. Blacher J, Guerin AP, Pannier B, Marchais SJ, Safar ME, London GM. Impact of aortic stiffness on survival in end-stage renal disease. Circulation. (1999) 99:2434-9. doi: 10.1161/01.CIR.99.18.2434

18. Kim J, Song TJ, Song D, Lee KJ, Kim EH, Lee HS, et al. Brachialankle pulse wave velocity is a strong predictor for mortality in patients with acute stroke. Hypertension. (2014) 64:240-6. doi: 10.1161/HYPERTENSIONAHA.114.03304

19. Feistritzer HJ, Klug G, Reinstadler SJ, Reindl M, Niess L, Nalbach $\mathrm{T}$, et al. Prognostic value of aortic stiffness in patients after stelevation myocardial infarction. J Am Heart Assoc. (2017) 6:e005590. doi: 10.1161/JAHA.117.005590

20. Ki YJ, Choi DH, Lee YM, Lim L, Song H, Koh YY. Predictive value of brachial-ankle pulse wave velocity for long-term clinical outcomes after percutaneous coronary intervention in a Korean cohort. Int J Cardiol. (2014) 175:554-9. doi: 10.1016/j.ijcard.2014.06.032

21. van Sloten TT, Sedaghat S, Laurent S, London GM, Pannier B, Ikram MA, et al. Carotid stiffness is associated with incident stroke: a systematic review and individual participant data meta-analysis. J Am Coll Cardiol. (2015) 66:2116-25. doi: 10.1016/j.jacc.2015.08.888

22. Sugawara J, Hayashi K, Tanaka H. Arterial path length estimation on brachial-ankle pulse wave velocity: validity of height-based formulas. J Hypertens. (2014) 32:881-9. doi: 10.1097/HJH.00000000000 00114

23. Laurent S, Cockcroft J, Van Bortel L, Boutouyrie P, Giannattasio C, Hayoz D, et al. Expert consensus document on arterial stiffness: methodological issues and clinical applications. Eur Heart J. (2006) 27:2588605. doi: 10.1093/eurheartj/ehl254

24. Podolec P, Kopec G, Podolec J, Wilkolek P, Krochin M, Rubis P, et al. Aortic pulse wave velocity and carotid-femoral pulse wave velocity: similarities and discrepancies. Hypertens Res. (2007) 30:1151-8. doi: 10.1291/hypres. 30.1151
25. Munakata M. Brachial-ankle pulse wave velocity in the measurement of arterial stiffness: recent evidence and clinical applications. Curr Hypertens Rev. (2014) 10:49-57. doi: 10.2174/157340211001141111 160957

26. Witteman JC, Grobbee DE, Valkenburg HA, van Hemert AM, Stijnen $\mathrm{T}$, Burger $\mathrm{H}$, et al. J-shaped relation between change in diastolic blood pressure and progression of aortic atherosclerosis. Lancet. (1994) 343:504-7. doi: 10.1016/S0140-6736(94)91459-1

27. Hennekens $\mathrm{CH}$. Increasing burden of cardiovascular disease current knowledge and future directions for research on risk factors. Circulation. (1998) 97:1095-102. doi: 10.1161/01.CIR.97.11. 1095

28. Myerburg RJ, Interian A Jr, Mitrani RM, Kessler KM, Castellanos A. Frequency of sudden cardiac death and profiles of risk. Am J Cardiol. (1997) 80:10f-9. doi: 10.1016/S0002-9149(97)00477-3

29. Choi EK, Choi SI, Rivera JJ, Nasir K, Chang SA, Chun EJ, et al. Coronary computed tomography angiography as a screening tool for the detection of occult coronary artery disease in asymptomatic individuals. J Am Coll Cardiol. (2008) 52:357-65. doi: 10.1016/j.jacc.2008. 02.086

30. Bechlioulis A, Vakalis K, Naka KK, Bourantas CV, Papamichael ND, Kotsia $A$, et al. Increased aortic pulse wave velocity is associated with the presence of angiographic coronary artery disease in overweight and obese patients. Am J Hypertens. (2013) 26:265-70. doi: 10.1093/ajh/hps039

31. Chiha J, Mitchell P, Gopinath B, Burlutsky G, Plant A, Kovoor P, et al. Prediction of coronary artery disease extent and severity using pulse wave velocity. PLoS ONE. (2016) 11:e0168598. doi: 10.1371/journal.pone.016 8598

32. Duman OO, Goldeli O, Gursul E, Baris N, Ozpelit E, Simsek MA. The value of aortic pulse wave velocity in predicting coronary artery disease diagnosis and severity. Acta Cardiol. (2015) 70:315-22. doi: 10.1080/AC.70.3.308 0636

33. Funck KL, Laugesen E, Ovrehus K, Jensen JM, Norgaard BL, Dey $\mathrm{D}$, et al. Increased high-risk coronary plaque burden is associated with arterial stiffness in patients with type 2 diabetes without clinical signs of coronary artery disease: a computed tomography angiography study. J Hypertens. (2017) 35:1235-43. doi: 10.1097/HJH.00000000000 01308

34. Hofmann B, Riemer M, Erbs C, Plehn A, Navarrete Santos A, Wienke A, et al. Carotid to femoral pulse wave velocity reflects the extent of coronary artery disease. J Clin Hypertens. (2014) 16:629-33. doi: 10.1111/jch.1 2382

35. Braber TL, Prakken NH, Mosterd A, Mali WP, Doevendans PA, Bots ML, et al. Identifying coronary artery disease in asymptomatic middle-aged sportsmen: the additional value of pulse wave velocity. PLOS ONE. (2015) 10:e0131895. doi: 10.1371/journal.pone.0131895

36. Chae MJ, Jung IH, Jang DH, Lee SY, Hyun JY, Jung JH, et al. The brachial ankle pulse wave velocity is associated with the presence of significant coronary artery disease but not the extent. Korean Circ J. (2013) 43:239-45. doi: 10.4070/kcj.2013.43.4.239

37. Chung CM, Yang TY, Lin YS, Chang ST, Hsiao JF, Pan KL, et al. Relation of arterial stiffness assessed by brachial-ankle pulse wave velocity to complexity of coronary artery disease. Am J Med Sci. (2014) 348:294-9. doi: 10.1097/MAJ.00000000000 00285

38. Kim BH, Jang JS, Kwon YS, Kim JH, Kim IJ, Lee CW. High brachial ankle pulse wave velocity as a marker for predicting coronary artery stenosis in patients with type 2 diabetes. Endocrinol Metab. (2018) 33:88-96. doi: 10.3803/EnM.2018.33.1.88

39. Kim HL, Jin KN, Seo JB, Choi YH, Chung WY, Kim SH, et al. The association of brachial-ankle pulse wave velocity with coronary artery disease evaluated by coronary computed tomography angiography. PLoS ONE. (2015) 10:e0123164. doi: 10.1371/journal.pone. 0123164

40. Kim JH, Rhee MY, Kim YS, Bae JH, Nah DY, Kim YK, et al. Brachialankle pulse wave velocity for the prediction of the presence and severity of coronary artery disease. Clin Exp Hypertens. (2014) 36:404-9. doi: $10.3109 / 10641963.2013 .846354$ 
41. Lee JY, Ryu S, Lee SH, Kim BJ, Kim BS, Kang JH, et al. Association between brachial-ankle pulse wave velocity and progression of coronary artery calcium: a prospective cohort study. Cardiovasc Diabetol. (2015) 14:147. doi: 10.1186/s12933-015-0311-3

42. Nam HJ, Jung IH, Kim J, Kim JH, Suh J, Kim HS, et al. Association between brachial-ankle pulse wave velocity and occult coronary artery disease detected by multi-detector computed tomography. Int J Cardiol. (2012) 157:227-32. doi: 10.1016/j.ijcard.2011.01.045

43. Torii S, Arima H, Ohkubo T, Fujiyoshi A, Kadota A, Takashima N, et al. Association between pulse wave velocity and coronary artery calcification in Japanese men. J Atheroscl Thromb. (2015) 22:1266-77. doi: 10.5551/jat.30247

44. Vishnu A, Choo J, Wilcox B, Hisamatsu T, Barinas-Mitchell EJ, Fujiyoshi A, et al. Brachial-ankle pulse wave velocity is associated with coronary calcification among 1131 healthy middle-aged men. Int J Cardiol. (2015) 189:67-72. doi: 10.1016/j.ijcard.2015.04.020

45. Xiong Z, Zhu C, Zheng Z, Wang M, Wu Z, Chen L, et al. Relationship between arterial stiffness assessed by brachial-ankle pulse wave velocity and coronary artery disease severity assessed by the SYNTAX score. J Atheroscl Thromb. (2012) 19:970-6. doi: 10.5551/jat.13326

46. Cainzos-Achirica M, Rampal S, Chang Y, Ryu S, Zhang Y, Zhao $\mathrm{D}$, et al. Brachial-ankle pulse wave velocity is associated with coronary calcium in young and middle-aged asymptomatic adults: the Kangbuk Samsung Health Study. Atherosclerosis. (2015) 241:350-6. doi: 10.1016/j.atherosclerosis.2015.05.031

47. Pantoni L. Cerebral small vessel disease: from pathogenesis and clinical characteristics to therapeutic challenges. Lancet Neurol. (2010) 9:689-701. doi: 10.1016/S1474-4422(10)70104-6

48. Wardlaw JM, Smith EE, Biessels GJ, Cordonnier C, Fazekas F, Frayne R, et al. Neuroimaging standards for research into small vessel disease and its contribution to ageing and neurodegeneration. Lancet Neurol. (2013) 12:822-38. doi: 10.1016/S1474-4422(13)70124-8

49. Ochi N, Tabara Y, Igase M, Nagai T, Kido T, Miki T, et al. Silent cerebral microbleeds associated with arterial stiffness in an apparently healthy subject. Hypertens Res. (2009) 32:255-60. doi: 10.1038/hr.2009.13

50. Zhai FF, Ye YC, Chen SY, Ding FM, Han F, Yang XL, et al. Arterial stiffness and cerebral small vessel disease. Front Neurol. (2018) 9:723. doi: 10.3389/fneur.2018.00723

51. Kim J, Cha MJ, Lee DH, Lee HS, Nam CM, Nam HS, et al. The association between cerebral atherosclerosis and arterial stiffness in acute ischemic stroke. Atherosclerosis. (2011) 219:887-91. doi: 10.1016/j.atherosclerosis.2011.09.013

52. Kim YB, Park KY, Chung PW, Kim JM, Moon HS, Youn YC. Brachial-ankle pulse wave velocity is associated with both acute and chronic cerebral small vessel disease. Atherosclerosis. (2016) 245:54-9. doi: 10.1016/j.atherosclerosis.2015.12.006

53. Kim DH, Choi JH, Moon JS, Kim HJ, Cha JK. Association between the severity of cerebral small vessel disease, pulsatility of cerebral arteries, and brachial ankle pulse wave velocity in patients with lacunar infarction. Eur Neurol. (2010) 64:247-52. doi: 10.1159/000319923

54. Tabata N, Sueta D, Yamashita T, Utsunomiya D, Arima Y, Yamamoto E, et al. Relationship between asymptomatic intra-cranial lesions and brachialankle pulse wave velocity in coronary artery disease patients without stroke. Hypertens Res. (2017) 40:392-8. doi: 10.1038/hr.2016.159

55. Henskens LH, Kroon AA, van Oostenbrugge RJ, Gronenschild $\mathrm{EH}$, Fuss-Lejeune MM, Hofman PA, et al. Increased aortic pulse wave velocity is associated with silent cerebral small-vessel disease in hypertensive patients. Hypertension. (2008) 52:1120-6. doi: 10.1161/HYPERTENSIONAHA.108.119024

56. Poels MM, Zaccai K, Verwoert GC, Vernooij MW, Hofman A, van der Lugt $\mathrm{A}$, et al. Arterial stiffness and cerebral small vessel disease: the Rotterdam Scan Study. Stroke. (2012) 43:2637-42. doi: 10.1161/STROKEAHA.111.642264

57. Rosano C, Watson N, Chang Y, Newman AB, Aizenstein HJ, Du Y, et al. Aortic pulse wave velocity predicts focal white matter hyperintensities in a biracial cohort of older adults. Hypertension. (2013) 61:160-5. doi: 10.1161/HYPERTENSIONAHA.112.198069

58. Brandts A, van Elderen SG, Westenberg JJ, van der Grond J, van Buchem MA, Huisman MV, et al. Association of aortic arch pulse wave velocity with left ventricular mass and lacunar brain infarcts in hypertensive patients: assessment with MR imaging. Radiology. (2009) 253:681-8. doi: 10.1148/radiol.2533082264

59. King KS, Chen KX, Hulsey KM, McColl RW, Weiner MF, Nakonezny PA, et al. White matter hyperintensities: use of aortic arch pulse wave velocity to predict volume independent of other cardiovascular risk factors. Radiology. (2013) 267:709-17. doi: 10.1148/radiol.13121598

60. van Elderen SG, Brandts A, Westenberg JJ, van der Grond J, Tamsma JT, van Buchem MA, et al. Aortic stiffness is associated with cardiac function and cerebral small vessel disease in patients with type 1 diabetes mellitus: assessment by magnetic resonance imaging. Eur Radiol. (2010) 20:1132-8. doi: 10.1007/s00330-009-1655-4

61. Taniguchi Y, Fujiwara Y, Nofuji Y, Nishi M, Murayama H, Seino S, et al. Prospective study of arterial stiffness and subsequent cognitive decline among community-dwelling older Japanese. J Epidemiol. (2015) 25:592-9. doi: 10.2188/jea.JE20140250

62. Li X, Lyu P, Ren Y, An J, Dong Y. Arterial stiffness and cognitive impairment. J Neurol Sci. (2017) 380:1-10. doi: 10.1016/j.jns.2017.06.018

63. Zhang J, Li Y, Wang Y, Niu W, Zhang Y, Gao P, et al. Arterial stiffness and asymptomatic intracranial large arterial stenosis and calcification in hypertensive chinese. Am J Hypertens. (2011) 24:304-9. doi: 10.1038/ajh.2010.246

64. De Silva DA, Woon FP, Gan HY, Chen CP, Chang HM, Koh TH, et al. Arterial stiffness is associated with intracranial large artery disease among ethnic Chinese and South Asian ischemic stroke patients. J Hypertens. (2009) 27:1453-8. doi: 10.1097/HJH.0b013e32832a8dc5

65. Yokokawa H, Goto A, Watanabe K, Yasumura S. Evaluation of atherosclerosis-associated factors and pulse wave velocity for predicting cerebral infarction: a hospital-based, case-control study in Japan. Intern Med J. (2007) 37:161-7. doi: 10.1111/j.1445-5994.2006.01278.x

66. Park KY, Kim YB, Moon HS, Suh BC, Chung PW. Association between cerebral arterial calcification and brachial-ankle pulse wave velocity in patients with acute ischemic stroke. Eur Neurol. (2009) 61:364-70. doi: 10.1159/000210549

67. Choi JC, Lee JS, Kang SY, Kang JH, Bae JM, Lee DH. Limitation of brachial-ankle pulse wave velocity in assessing the risk of stroke: importance of instantaneous blood pressure. Cerebrovasc Dis. (2009) 27:41725. doi: 10.1159/000209236

68. O’Leary DH, Polak JF, Kronmal RA, Manolio TA, Burke GL, Wolfson SK, Jr. Carotid-artery intima and media thickness as a risk factor for myocardial infarction and stroke in older adults. Cardiovascular Health Study Collaborative Research Group. N Engl J Med. (1999) 340:14-22. doi: 10.1056/NEJM199901073400103

69. Nambi V, Chambless L, Folsom AR, He M, Hu Y, Mosley T, et al. Carotid intima-media thickness and presence or absence of plaque improves prediction of coronary heart disease risk: the ARIC (Atherosclerosis Risk In Communities) study. J Am Coll Cardiol. (2010) 55:1600-7. doi: 10.1016/j.jacc.2009.11.075

70. Shen L, Wu W, You B, Gao H, Wang C, Liu Y. Relationship between pulse wave velocity and carotid atherosclerosis in geriatric people. Cerebrovasc Dis. (2011) 32(Suppl. 1):16-20. doi: 10.1159/00033 0316

71. Lu Y, Zhu M, Bai B, Chi C, Yu S, Teliewubai J, et al. Comparison of carotid-femoral and brachial-ankle pulse-wave velocity in association with target organ damage in the community-dwelling elderly Chinese: the Northern Shanghai Study. J Am Heart Assoc. (2017) 6:e004168. doi: 10.1161/JAHA.116.004168

72. Taniwaki H, Kawagishi T, Emoto M, Shoji T, Kanda H, Maekawa K, et al. Correlation between the intima-media thickness of the carotid artery and aortic pulse-wave velocity in patients with type 2 diabetes. Vessel wall properties in type 2 diabetes. Diabetes Care. (1999) 22:1851-7. doi: $10.2337 /$ diacare.22.11.1851

73. Zureik M, Temmar M, Adamopoulos C, Bureau JM, Courbon D, Thomas F, et al. Carotid plaques, but not common carotid intima-media thickness, are independently associated with aortic stiffness. J Hypertens. (2002) 20:85-93. doi: 10.1097/00004872-200201000-00013

74. Sumbul HE, Koc AS, Demirtas D. Increased carotid-femoral pulse wave velocity and common carotid artery intima-media thickness obtained to 
assess target organ damage in hypertensive patients are closely related. Clin Exp Hypertens. (2018). doi: 10.1080/10641963.2018.1506471. [Epub ahead of print].

75. Kubozono T, Miyata M, Kawasoe S, Ojima S, Yoshifuku S, Miyahara $\mathrm{H}$, et al. High pulse wave velocity has a strong impact on early carotid atherosclerosis in a Japanese general male population. Circ J. (2017) 81:3105. doi: 10.1253/circj.CJ-16-0687

76. Joo HJ, Cho SA, Cho JY, Lee S, Park JH, Hwang SH, et al. Brachialankle pulse wave velocity is associated with composite carotid and coronary atherosclerosis in a middle-aged asymptomatic population. J Atheroscl Thromb. (2016) 23:1033-46. doi: 10.5551/jat.33084

77. Masugata H, Senda S, Yoshikawa K, Yoshihara Y, Daikuhara H, Ayada Y, et al. Relationships between echocardiographic findings, pulse wave velocity, and carotid atherosclerosis in type 2 diabetic patients. Hypertens Res. (2005) 28:965-71. doi: 10.1291/hypres.28.965

78. Munakata M, Sakuraba J, Tayama J, Furuta T, Yusa A, Nunokawa T, et al. Higher brachial-ankle pulse wave velocity is associated with more advanced carotid atherosclerosis in end-stage renal disease. Hypertens Res. (2005) 28:9-14. doi: 10.1291/hypres.28.9

79. Tomonori T, Keiko S, Shinkichi H, Yoji N, Akira T. Carotid atherosclerosis and arterial peripheral pulse wave velocity in cerebral thrombosis. J Clin Neurosci. (2006) 13:45-9. doi: 10.1016/j.jocn.2005. 02.012

80. Fu X, Liu Q, Zeng X, Huang S, Huang R, Gao Q. Association between cerebral arterial stiffness and large artery atherosclerosis in acute ischemic stroke. J Stroke Cerebrovasc Dis. (2018) 27:2993-3000. doi: 10.1016/j.jstrokecerebrovasdis.2018.06.033

81. Koivistoinen $\mathrm{T}$, Virtanen $\mathrm{M}$, Hutri-Kahonen $\mathrm{N}$, Lehtimaki $\mathrm{T}$, Jula A, Juonala $\mathrm{M}$, et al. Arterial pulse wave velocity in relation to carotid intima-media thickness, brachial flow-mediated dilation and carotid artery distensibility: the Cardiovascular Risk in Young Finns Study and the Health 2000 Survey. Atherosclerosis. (2012) 220:387-93. doi: 10.1016/j.atherosclerosis.2011.08.007

82. Li C, Xiong H, Pirbhulal S, Wu D, Li Z, Huang W, et al. Heart-carotid pulse wave velocity a useful index of atherosclerosis in chinese hypertensive patients. Medicine. (2015) 94:e2343. doi: 10.1097/MD.00000000000 02343

83. Yang Y, Fan F, Kou M, Yang Y, Cheng G, Jia J, et al. Brachial-ankle pulse wave velocity is associated with the risk of new carotid plaque formation: data from a chinese community-based cohort. Sci Rep. (2018) 8:7037. doi: 10.1038/s41598-018-25579-2

84. Zhao XX, Liu J, Zhao H, Zhou Y, Li L, Wang H. The effect of cardiovascular risk factors on the carotid intima-media thickness in an old-aged cohort with hypertension: a longitudinal evolution with 4-year follow-up of a random clinical trial. Clin Exp Hypertens. (2018) 41:49-57. doi: 10.1080/10641963.2018.1441860

85. Zhong Q, Hu MJ, Cui YJ, Liang L, Zhou MM, Yang YW, et al. Carotidfemoral pulse wave velocity in the prediction of cardiovascular events and mortality: an updated systematic review and meta-analysis. Angiology. (2018) 69:617-29. doi: 10.1177/0003319717742544

86. Ben-Shlomo Y, Spears M, Boustred C, May M, Anderson SG, Benjamin EJ, et al. Aortic pulse wave velocity improves cardiovascular event prediction: an individual participant meta-analysis of prospective observational data from 17,635 subjects. J Am Coll Cardiol. (2014) 63:636-46. doi: 10.1016/j.jacc.2013.09.063

87. Ohkuma T, Ninomiya T, Tomiyama H, Kario K, Hoshide S, Kita Y, et al. Brachial-ankle pulse wave velocity and the risk prediction of cardiovascular disease: an individual participant data meta-analysis. Hypertension. (2017) 69:1045-52. doi: 10.1161/HYPERTENSIONAHA.117.09097

88. Lim HE, Park CG, Shin SH, Ahn JC, Seo HS, Oh DJ. Aortic pulse wave velocity as an independent marker of coronary artery disease. Blood Press. (2004) 13:369-75. doi: 10.1080/080370504100 04800

89. Lee HS, Kim HL, Kim H, Hwang D, Choi HM, Oh SW, et al. Incremental prognostic value of brachial-ankle pulse wave velocity to single-photon emission computed tomography in patients with suspected coronary artery disease. J Atheroscl Thromb. (2015) 22:1040-50. doi: 10.5551/jat.2 9918
90. Williams B, Mancia G, Spiering W, Agabiti Rosei E, Azizi M, Burnier M, et al 2018 ESC/ESH Guidelines for the management of arterial hypertension. Eur Heart J. (2018) 39:3021-104. doi: 10.1093/eurheartj/ehy339

91. Dao HH, Essalihi R, Bouvet C, Moreau P. Evolution and modulation of age-related medial elastocalcinosis: impact on large artery stiffness and isolated systolic hypertension. Cardiovasc Res. (2005) 66:307-17. doi: 10.1016/j.cardiores.2005.01.012

92. Zieman SJ, Melenovsky V, Kass DA. Mechanisms, pathophysiology, and therapy of arterial stiffness. Arterioscler Thromb Vasc Biol. (2005) 25:932-43. doi: 10.1161/01.ATV.0000160548.78317.29

93. Intengan HD, Schiffrin EL. Vascular remodeling in hypertension: roles of apoptosis, inflammation, and fibrosis. Hypertension. (2001) 38(3 Pt 2):581-7. doi: $10.1161 /$ hy09t1.096249

94. Palombo C, Kozakova M. Arterial stiffness, atherosclerosis and cardiovascular risk: Pathophysiologic mechanisms and emerging clinical indications. Vasc Pharmacol. (2016) 77:1-7. doi: 10.1016/j.vph.2015.11.083

95. Dart AM, Kingwell BA. Pulse pressure-a review of mechanisms and clinical relevance. J Am Coll Cardiol. (2001) 37:975-84. doi: 10.1016/S0735-1097(01)01108-1

96. Leung MC, Meredith IT, Cameron JD. Aortic stiffness affects the coronary blood flow response to percutaneous coronary intervention. Am J Physiol Heart Circ Physiol. (2006) 290:H624-30. doi: 10.1152/ajpheart.00380.2005

97. Saji N, Shimizu H, Kawarai T, Tadano M, Kita Y, Yokono K. Clinical features of a first-ever lacunar infarction in Japanese patients: poor outcome in females. J Stroke Cerebrovasc Dis. (2011) 20:231-5. doi: 10.1016/j.jstrokecerebrovasdis.2009.12.005

98. Kandula NR, Kanaya AM, Liu K, Lee JY, Herrington D, Hulley SB, et al. Association of 10-year and lifetime predicted cardiovascular disease risk with subclinical atherosclerosis in South Asians: findings from the Mediators of Atherosclerosis in South Asians Living in America (MASALA) study. J Am Heart Assoc. (2014) 3:e001117. doi: 10.1161/JAHA.114.001117

99. Saji N, Kimura K, Kawarai T, Shimizu H, Kita Y. Arterial stiffness and progressive neurological deficit in patients with acute deep subcortical infarction. Stroke. (2012) 43:3088-90. doi: 10.1161/STROKEAHA.112.670737

100. Malik S, Wong ND. Metabolic syndrome, cardiovascular risk and screening for subclinical atherosclerosis. Expert Rev Cardiovasc Ther. (2009) 7:273-80. doi: 10.1586/14779072.7.3.273

101. Law MR, Wald NJ, Morris JK. The performance of blood pressure and other cardiovascular risk factors as screening tests for ischaemic heart disease and stroke. J Med Screen. (2004) 11:3-7. doi: 10.1177/096914130301100102

102. Brindle P, Beswick A, Fahey T, Ebrahim S. Accuracy and impact of risk assessment in the primary prevention of cardiovascular disease: a systematic review. Heart. (2006) 92:1752-9. doi: 10.1136/hrt.2006.087932

103. Goff DC Jr, Lloyd-Jones DM, Bennett G, Coady S, D'Agostino RB, Sr., Gibbons R, et al. 2013 ACC/AHA guideline on the assessment of cardiovascular risk: a report of the American College of Cardiology/American Heart Association Task Force on Practice Guidelines. J Am Coll Cardiol. (2014) 63(25 Pt B):2935-59. doi: 10.1016/j.jacc. 2013.11.005

104. Hwang IC, Jin KN, Kim HL, Kim YN, Im MS, Lim WH, et al. Additional prognostic value of brachial-ankle pulse wave velocity to coronary computed tomography angiography in patients with suspected coronary artery disease. Atherosclerosis. (2018) 268:127-37. doi: 10.1016/j.atherosclerosis.2017.11.026

105. Jang K, Kim HL, Park M, Oh S, Oh SW, Lim WH, et al. Additional value of brachial-ankle pulse wave velocity to single-photon emission computed tomography in the diagnosis of coronary artery disease. J Atheroscl Thromb. (2017) 24:1249-57. doi: 10.5551/jat.40071

106. Nielsen BL, Nielsen JS, Roin J, Fabricius J. Carotid-femoral pulse wave velocity. J Am Geriatr Soc. (1968) 16:658-65. doi: 10.1111/j.1532-5415.1968.tb01274.x

107. Laurent S, Cockcroft J, Van Bortel L, Boutouyrie P, Giannattasio C, Hayoz Daniel, et al. Abridged version of the expert consensus document on arterial stiffness. Artery Res. (2007) 1:2-12. doi: 10.1016/j.artres.2007.0 3.003

108. Van Bortel LM, Laurent S, Boutouyrie P, Chowienczyk P, Cruickshank JK, De Backer T, et al. Expert consensus document on the measurement 
of aortic stiffness in daily practice using carotid-femoral pulse wave velocity. J Hypertens. (2012) 30:445-8. doi: 10.1097/HJH.0b013e32834 fa8b0

109. Yamashina A, Tomiyama H, Takeda $\mathrm{K}$, Tsuda H, Arai T, Hirose $\mathrm{K}$, et al. Validity, reproducibility, and clinical significance of noninvasive brachialankle pulse wave velocity measurement. Hypertens Res. (2002) 25:359-64. doi: 10.1291/hypres.25.359

110. Sugawara J, Tanaka H. Brachial-ankle pulse wave velocity: myths, misconceptions, and realities. Pulse. (2015) 3:106-13. doi: 10.1159/00043 0771

111. Ato D. Pitfalls in the ankle-brachial index and brachial-ankle pulse wave velocity. Vasc Health Risk Manag. (2018) 14:41-62. doi: 10.2147/VHRM.S15 9437
112. Munakata M. Brachial-ankle pulse wave velocity: background, method, and clinical evidence. Pulse. (2016) 3:195-204. doi: 10.1159/000443740

Conflict of Interest Statement: The authors declare that the research was conducted in the absence of any commercial or financial relationships that could be construed as a potential conflict of interest.

Copyright $(2019$ Kim and Kim. This is an open-access article distributed under the terms of the Creative Commons Attribution License (CC BY). The use, distribution or reproduction in other forums is permitted, provided the original author(s) and the copyright owner(s) are credited and that the original publication in this journal is cited, in accordance with accepted academic practice. No use, distribution or reproduction is permitted which does not comply with these terms. 